\title{
Place attachment and acceptance of smart city technologies
}

\author{
Anna Wnuk \\ University of Warsaw \\ anna.wnuk@psych.uw.edu.pl
}

\author{
Tomasz Oleksy \\ University of Warsaw \\ tomasz.oleksy@psych.uw.edu.pl
}

\begin{abstract}
Recent studies on smart cities have emphasised that smart solution initiatives should take into account citizens' different needs and concerns. The main aim of this paper is to examine the role of different types of place attachment - emotional bonds that residents have with their city - in predicting the acceptance of future smart city technologies. In our study conducted among residents of multiple cities in Poland $(N=627)$, we found that while active place attachment (i.e. conscious identification with a place) predicted more favourable attitudes towards enabling technologies, traditional (natural and unintentional) place attachment was positively associated with acceptance of surveillance technologies regarding everyday monitoring and antiCovid-19 measures. We also found that the relationship between place attachment and acceptance of future technologies is partially mediated by the use of existing smart city technologies. The implications for city governments and planners are discussed.
\end{abstract}

\section{Introduction}

Changes are inherent aspects of city life, and technological shifts are crucial in the process of urban growth. The evolution of cities has always been related to technology, which has, over the centuries, modified how people live, work and relax in urban space. Today, cities are still on the front line of testing and implementing new technological modifications, as reflected in the growing popularity of the concept of the smart city - a place where innovative information technologies are a fundamental part of governmental processes and urban modernisation [1], [2]. From autonomous vehicles and transport drones to new security systems such as facial recognition technology, future technology will, doubtlessly, once again profoundly influence the daily lives of people in cities. Technological changes may even be accelerated by the Covid-19 pandemic, as cities have become the arena where the consequences of the pandemic are the most visible. All these factors have already made city authorities rethink what is a healthy and safe space for citizens. In some cities, small-scale solutions have already been introduced: There are bus shelters made of antiseptic glass, contactless hand disinfection machines, drones spraying disinfectant or cameras identifying body temperature. Some governments (e.g. in Israel, Singapore and China) have gone further during the Covid-19 pandemic and have used smartphone applications that enable the identification of those who may be potentially infected or in violation of anti-pandemic restrictions, see e.g. [3], [4].

However, technological changes in a city do not automatically have to be accepted by its inhabitants, nor do they immediately translate into increased quality of life. One criticism of the smart city concept is that it rarely considers the local context and values important for the city's residents [5]. Instead, the smart city has often been presented as a unified phenomenon that can be governed in corporate-like manner [6], [7]. Understanding the attitudes of residents towards technological changes may be particularly critical, as technology cannot be treated as neutral - numerous studies have shown that new technologies have a substantial impact on social life, changing the quality of personal relationships [8], [9], the concept of proximity [10]; and ideas of authority, privacy, liberty and democracy [11], [12]. Considering these issues, a crucial challenge for urban governments and businesses is to understand and consider individual characteristics that make technological changes less acceptable for some residents than for others (see also [13]). We argue that since new urban technologies will inevitably change both the urban space and the lives of inhabitants, the bonds of the inhabitants with the place - in other words, place attachment - should be considered in city policies.

\section{Place attachment and technological changes in (smart) cities}

Place attachment can be defined as an emotional bond with certain places, typically related to both their physical and their social aspects [14], [15]. This bond may stem from various meanings, including individual experience, length of residence or the historical and 
cultural significance of a place [15]. People may feel attachment to different-sized environments, such as the home [16], neighbourhood [17], [18] or city [19] - and it is the last type of attachment that is of the most interest to us in our study. Place attachment has numerous beneficial consequences for people's lives, as it predicts well-being [20], [21], stress reduction [22], perceived belongingness [23], one's feeling of security and self-esteem [24]. Compared to their peers, highly attached people more often possess proenvironmental attitudes related to a given place [25], [26] are more concerned about risky environmental changes [27] and are more willing to engage in activism aimed at protecting and caring for places [28]. Place attachment has also been linked to placeprotectionist attitudes and tactics for countering unwelcome changes [29] or opposition to remove symbolic but controversial monuments [30]. Some researchers have treated place attachment as one facet of social capital [31] and as an important factor contributing to social cohesion [32], which connects members of a local community and increases their quality of life.

Numerous researchers have suggested that place attachment becomes particularly salient when places change or become unavailable [33], [34], [35]. The destruction or excessive modification of a place can result in negative emotions, potentially causing anxiety, grief and even depression [36], [37], [38], [39]. The breaking of bonds between an individual and a place - a place disruption - can be caused by changes of various kinds: social, physical or symbolic [40]. Each type of change can evoke a sense of subjective loss. Residents who experience place disruption can use various coping strategies [41] from protective actions [42] [14], to acceptance and adaptation [42]. In addition, highly attached residents can support changes in a place if they evaluate a disruption positively, as Verbrugge and Van Den Born [43] reported in the context of flood safety improvements that changed a river landscape. What is more, rapid but positive changes can even make place attachment stronger, as von Wirth et al. [44] found in the context of urban growth.

The technological transformation of cities constitutes a major change - one that is not necessarily positive for all inhabitants. However, despite the role that place attachment plays in understanding the residents' attitudes to changes in their place of living, almost no studies have yet examined place attachment's relationship with the acceptance of future technological solutions that may soon become ubiquitous in cities. Existing research has mostly focused on the link between place attachment and the use of current city technologies [2]. We argue that the relation between place attachment and the acceptance of new technologies can be complex. On the one hand, technologies can enable new ways of using and exploring the city, improving quality of life and safety. On the other hand, technology can increase the distance between inhabitants and the city, as a new layers of virtuality may generate higher complexity and new dimensions of exclusion [45] and may also be a threat to residents' privacy [46]. To solve this puzzle, in our research, we consider different types of place attachment - active and traditional - as well as different types of future technologies: 1) enabling technologies, such as autonomous vehicles, transport drones or care robots; 2) everyday surveillance technologies, such as monitoring drones or facial recognition technologies; and 3) anti-Covid-19 monitoring technologies, such as thermal scanners or drones monitoring social distancing. Distinguishing between two types of attachment allows us to respond to ambiguous results concerning the relationship between attachment and attitudes towards changes in a city. Additionally, we examine whether the relationship between place attachment and acceptance of future technologies is mediated by the use of existing smart city technologies.

For this study, we used the place attachment typology developed by Lewicka [47], who differentiated between active and traditional place attachment. Traditional place attachment is characterised by a feeling of rootedness and a simple, unintentional relationship between inhabitants and a place. This form of attachment is mostly shaped by length of residency, biographical events and habitual, daily activities. Traditionally attached people treat their place of living as a location that cannot be replaced by any other; they declare that even if there were better places to live, they would not decide to move. As traditional attachment is strongly linked to being accustomed to a place, we assumed that it is associated with greater resistance to technological changes, as traditionally attached people may perceive the presence of new technologies as a threat and unwanted change. Moreover, profile analyses of individuals with higher traditional place attachment have shown that these people have relatively less cultural capital and affirm more conservative values than actively attached individuals [47]. Numerous studies have demonstrated that cultural conservatism is often related to an increased need for security and control over the environment [48], [49]. Therefore, we predicted the following:

H1a: Traditional place attachment is negatively related to acceptance of enabling technologies. 
H1b: Traditional place attachment is positively related to acceptance of both types of surveillance technologies.

In contrast, active place attachment is based on not habitual but more conscious identification with a place. With this type of attachment, a relationship between people and a place is discovered rather than inherited, and it can rest upon, for example, an interest in local history or opportunities offered by the city. Individuals who score high on active place attachment are willing to explore a city and enjoy interactions with the city. For this reason, we assumed that actively attached people present more positive attitudes towards future technologies changing the cityscape, as they may perceive these changes as elements of progress and as additional interesting opportunities making life in the city easier. However, the direction of the relationship between active place attachment and acceptance of surveillance technologies may be more difficult to predict. On the one hand, active place attachment is associated with relatively higher levels of cultural capital, broader social networks and higher levels of trust. Therefore, actively attached people may be more aware of the risks associated with the ubiquitous presence of surveillance technologies and may find these technologies unnecessary because of their higher level of trust. On the other hand, citizens with high active attachment may appreciate the increased level of safety provided by surveillance technologies because these technologies allow them to interact with the city even more comfortably and seamlessly. Thus, we predicted the following:

H2: Active place attachment is positively related to acceptance of enabling technologies.

We also examined the following research question: RQ1: Is active place attachment positively or negatively related to surveillance technologies?

The second aim of our research was to examine whether the relationship between place attachment and acceptance of future technologies is mediated by use of existing smart city technologies. A theoretical justification for 1) the relationship between place attachment and use of existing technologies and 2) the relationship between use of existing technologies and acceptance of future technologies is given below.

\section{Place attachment and use of existing smart city technologies}

Place attachment may be associated not only with a more positive attitude towards a city, but also with a plethora of behavioural reactions and tendencies [28]. Research has shown that place attachment influences civic activity aimed at protecting or improving one's place of living, manifested in both more sustainable or ecological behaviour and more negative reactions to encroachment [50], [51]. Importantly, place attachment is also related directly or indirectly to increased loyalty to a place [52], participation in grassroots community organisations [53], acceptance of local projects [54] and more intense uses of places [28].

Belanche, Casaló and Orús [2] examined whether another type of behaviour associated with higher place attachment is the increased use of urban technologies. They found that emotional bonds with a city indirectly affect use of urban services via positive perceptions of city-related entities. However, one limitation of this study was the use of a one-dimensional scale of place attachment. We believe that the distinction between traditional and active place attachment may again be important for understanding the above relationship. New urban technologies should be particularly attractive to actively attached citizens, who are interested in new ways of exploring and interacting with a city. On the other hand, traditionally attached people may see existing smart city technologies as unwanted changes and threats to their well-known place. Thus, we hypothesised the following:

H3a: Active place attachment is positively related to use of existing smart city technologies.

H3b: Traditional place attachment is negatively related to use of existing smart city technologies.

\section{Use of existing smart city technologies and acceptance of future technologies in the city}

Previous experience with technology may be an important factor in shaping positive attitudes towards new technologies. For example, Zmud and Sener [55] found that individuals who more frequently used smartphones, social media and transportation apps reported a higher willingness to use automated vehicles in the future. Similarly, Lee, Ward, Raue, D'Ambrosio and Coughlin [56] found that interest in using autonomous cars was related to self-reported experience with current technology in general and higher confidence in the use of new technologies. In the context of city technologies, the key question seems to be how much a positive relationship between the use of current technologies and acceptance of future ones depends on the perceived similarity between the technologies (see, for example, [57]). We hypothesise that the use of current technologies is more strongly associated with acceptance of enabling technologies than with acceptance of surveillance technologies due to both the distinct nature of the latter and the different types of needs they meet. 
However, frequent use of technology can accustom users to the idea that technology is inherently positive, trustworthy and able to make life easier, reducing their willingness to think critically about the possible consequences of new technological solutions, such as surveillance or privacy issues. Some support for this possibility stems from existing studies on permission requests in apps, which have suggested a potential risk of user desensitisation: The more a person uses an application, the more they become accustomed to accepting permission requests and, as a result, can ignore potential data security risks [58]. If a similar effect were to occur in the context of urban technologies, a positive relationship could be expected between the use of current technologies and greater acceptance of all three types of future technologies.

H4: Use of existing smart city technologies is related to increased acceptance of future enabling technologies.

We also examined following related research question:

RQ2: Is use of existing smart city technology related to acceptance of surveillance technologies?

Following our reasoning that active place attachment is positively related to the use of smart city technologies and, further, to acceptance of future enabling technologies, we expected the following:

H5a: Use of existing technologies mediates the positive effect of active place attachment on acceptance of enabling technologies.

Conversely, we hypothesised the following:

H5b: Traditional place attachment is negatively related to acceptance of future enabling technologies via decreased use of existing technologies.

We also explored the following research question:

RQ3: Does the use of smart city technologies explain the relation between the two types of place attachment and attitudes towards surveillance technologies?

Age and length of residence are correlated with place attachment [15], and age is related to attitudes towards new technologies [59], [60]. Moreover, political views may be correlated to traditional place attachment, and the size of the residence place and level of education may also be related to use of smart city technologies, as in small towns, smart city technologies are not as common as in big cities. With the above factors in mind, we developed our models with age, education, length of residence, size of residence place and political views as control variables.

\section{Method}

\subsection{Participants and procedure}

Six hundred twenty seven persons (60\% women) participated in an online study conducted on Facebook $^{1}$. We used Facebook advertisements to sample Polish citizens currently living in multiple cities sized at least 50000 residents. Participants were offered a possibility of remuneration (participation in a drawing of five vouchers worth c.a. 10\$). The sample consisted of people aged 18-75 $(M=35.93, S D=$ 13.21). The study was conducted from $16^{\text {th }}$ of May till $7^{\text {th }}$ of June.

\subsection{Measures}

Place attachment. We measured attachment to a city with the modified version of the place attachment scale developed by Lewicka [15], [47]. We focused on two sub-dimensions, active and traditional attachments. We measured active place attachment with a five-item scale $^{2}$ (e.g. 'I like to wander around my city and discover new places'), $\alpha=.83$. We assessed traditional place attachment with a three-item scale (e.g. 'I have never considered living somewhere else'), $\alpha=.85$. Participants answered on a seven-item Likert scale $(1=$ 'totally disagree' to $7=$ 'totally agree'). In the analyses, we used the mean value of the respective items.

Use of smart city technologies was measured by 13 items related to technologies that are now available in Polish cities, such as applications that help one to navigate in the city and to rent a bicycle or a car, or online platforms for contact with the city hall or town council. Participants were asked whether they use each technological solution and answered on the following scale: $0=$ 'no', $1=$ 'yes, but occasionally' and $2=$ 'yes, regularly'. In the analyses, we used the sum of participant' answers, $\alpha=.74$.

Acceptance of future smart city technologies was measured with three scales, the first corresponding to enabling technologies (e.g. 'computer programs designed for conversations [i.e. chatbots] replacing officials in the first contact with residents'), $\alpha=.76$. The second corresponded to everyday surveillance technologies (e.g. 'surveillance cameras with an automatic face recognition system to identify people who break the law'), $\alpha=.82$, and the third referred to anti-Covid-19 technologies designed to counteract the pandemic (e.g. 'applications based on automatic location of users, informing them that they have been in places where there is a risk of contracting the coronavirus'), $\alpha=.85$. The first two scales were specifically designed for this study based on measures

\footnotetext{
${ }^{1}$ Facebook users tend to be younger and better educated than the overall population, however, it was proven that Facebook samples can produce self-reported data of very high quality (see: [67]).

${ }^{2}$ Two items were added to test a new version of the scale, better suited to the theoretical concept.
} 
and solutions introduced in other countries. The scale referred to anti-Covid-19 technologies was previously used in the study done by Wnuk, Oleksy, Maison [61] and was based on anti-pandemic measures used in several states. Participants answered on a scale from 1 $=$ 'I would definitely not accept' to $7=$ 'I would definitely accept.'

Political views was measured with two items: "What are your moral views?" ( 1 = conservative, 7 = liberal) and "What are your economic views?" ( 1 = free market economy, 7 = social welfare state).

All the measures were presented in randomised order, and not all the participants filled out the entire questionnaire (some withdrew before the end), which is why the final samples vary for different measures.

\subsection{Analytical strategy}

The main aims of this study were to test the predictive role of place attachment in explaining acceptance of future smart city technologies and to explore the mechanism that underlies this relation. Therefore, the analyses were based on a mediation model with the two types of place attachment as independent variables, acceptance of three types of technologies as dependent variables and the use of smart city technologies as a mediating variable.

First, we checked the total relation between the independent variables and dependent variables. Second, we included the mediator and tested the full mediation model. In the next step, we checked the robustness of our results, and we added covariates to the model as predictors of the dependent variables and mediator. The analyses were performed using the path analysis framework with Mplus 7.0 software [62]. We used a robust maximum likelihood estimation (MLR) to account for the violation of multivariate normality.

\section{Results}

\subsection{Zero-order correlations}

The correlations between the main variables and covariates are presented in Table 1. Active place attachment was positively correlated with use of smart city technologies and with acceptance of both enabling and anti-Covid-19 surveillance technologies. Traditional place attachment was not related to use of current smart city technologies, but was negatively correlated with acceptance of enabling technologies and positively correlated with (both everyday and antiCovid-19) surveillance technologies. Use of smart city technologies was positively related only to acceptance of enabling technologies.

Older individuals and those who had lived longer in a given city were more traditionally attached to their city and exhibited a more favourable attitude towards surveillance technologies. On the other hand, younger participants were more in favour of enabling technologies. Residents of larger cities more often used smart city technologies and were simultaneously more opposed to the introduction of anti-Covid-19 surveillance technologies than residents of smaller cities and towns. Moral political views (i.e. liberal views) were positively correlated with active place attachment, use of smart city technologies and acceptance of enabling technologies, but negatively related with traditional place attachment.

\subsection{Path analysis}

The results of the path analysis demonstrate that while we accounted for the shared variance of both types of place attachment, active place attachment positively predicted acceptance of enabling technologies $(B=0.18, S E=0.05, p<0.001)$, and traditional place attachment was negatively related to these technologies $(B=-0.12, S E=0.03, p<0.001)$. Adding use of smart city technologies to the model diminished the effect of both active and traditional place attachment on acceptance of enabling technologies $(B=0.09, S E=0.05, p=0.05 ; B=-0.09$, $S E=0.03, p<0.01$, respectively).

In line with hypotheses, while we accounted for the shared variance of both types of place attachment, active attachment was positively and traditional attachment was negatively related to use of smart city technologies. Use of smart city technologies positively predicted attitudes towards enabling technologies. See Figure 1 for the exact coefficients.

The use of smart city technologies fully mediated the positive effect of active place attachment on acceptance of enabling technologies $(I E=0.09, S E=$ $0.02, p<0.001)$ and partially mediated the negative effect of traditional attachment $(I E=-0.04, S E=0.01$, $p<0.001)$. Active place attachment did not predict acceptance of any type of surveillance technologies, neither everyday nor anti-Covid-19 technologies $(B=$ $0.03, S E=0.07, p=0.63 ; B=0.09, S E=0.05, \mathrm{p}=$ 0.08 , respectively), while traditional place attachment was positively related to both types of surveillance technologies $(B=0.16, S E=0.05, p<0.01 ; B=0.11$,

$S E=0.04, p<0.01$, respectively). At the same time, use of smart cities technologies was not related to acceptance of any of these technologies (see Figure 1 for the exact coefficients) and did not account for the relationship between traditional attachment and these dependent variables.

The main results did not change when the covariates were introduced to the model; the relationship between both active and traditional place attachment and acceptance of enabling technologies 
was mediated by use of smart city technologies $(I E=$ $0.06, S E=0.02, p<0.001 ; I E=-0.03, S E=0.01, p<$ 0.01 , respectively). However, the total effect of traditional place attachment on acceptance of enabling technologies was insignificant, $B=-0.05 S E=0.05 p=$
.26. The effects of traditional place attachment on everyday $(B=0.11, S E=0.05, p<0.05)$ and antiCovid-19 $(B=0.13, S E=0.05, p<0.05)$ surveillance technologies remained significant.

Table 1. Means, standard deviations, and correlations between variables

\begin{tabular}{|c|c|c|c|c|c|c|c|c|c|c|c|c|c|}
\hline & $\mathrm{M}$ & SD & 2 & 3 & 4 & 5 & 6 & 7 & 8 & 9 & 10 & 11 & 12 \\
\hline $\begin{array}{l}\text { 1. Active place } \\
\text { attachment } \\
(N=591)\end{array}$ & 5.00 & 1.34 & $.35^{* *}$ & $.13^{* *}$ & .08 & $.13^{* *}$ & $.29^{* *}$ & .07 & $.09^{*}$ & $.15^{* *}$ & $.11^{* *}$ & .03 & .01 \\
\hline $\begin{array}{l}\text { 2. Traditional place } \\
\text { attachment } \\
(N=591)\end{array}$ & 3.02 & 1.70 & & $-.09^{*}$ & $.15^{* *}$ & $.15^{* *}$ & -.06 & $.37^{* *}$ & $.42^{* *}$ & -.01 & $-.11^{*}$ & -.07 & .00 \\
\hline $\begin{array}{l}\text { 3. Enabling } \\
\text { technologies } \\
(N=627)\end{array}$ & 5.22 & 1.32 & & & $.35^{* *}$ & $.38^{* *}$ & $.28^{* *}$ & $-.17^{* *}$ & $-.16^{* *}$ & .08 & $.29^{* *}$ & .01 & -.03 \\
\hline $\begin{array}{l}\text { 4. Everyday } \\
\text { surveillance } \\
\text { technologies } \\
(N=627)\end{array}$ & 3.87 & 1.85 & & & & $.65^{* *}$ & .00 & $.12^{* *}$ & $.09^{*}$ & -.06 & .03 & -.07 & -.03 \\
\hline $\begin{array}{l}\text { 5. Anti-Covid-19 } \\
\text { surveillance } \\
\text { technologies } \\
(N=614)\end{array}$ & 3.40 & 1.50 & & & & & .02 & .05 & .06 & $-.09^{*}$ & .04 & $.09^{*}$ & .04 \\
\hline $\begin{array}{l}\text { 6. Use of smart city } \\
\text { technologies } \\
(N=593)\end{array}$ & 12.25 & 4.62 & & & & & & .02 & -.07 & $.15^{* *}$ & $.24^{* *}$ & .07 & .02 \\
\hline 7. Age $(N=623)$ & 35.93 & 13.21 & & & & & & & $.70^{* *}$ & $-.14^{* *}$ & -.01 & .02 & .01 \\
\hline $\begin{array}{l}\text { 8. Length of residence } \\
\quad(N=618)\end{array}$ & 24.54 & 17.68 & & & & & & & & .02 & -.05 & .01 & .04 \\
\hline $\begin{array}{l}\text { 9. Size of residence } \\
\text { place }(N=627)\end{array}$ & 7.06 & 1.73 & & & & & & & & & $.14^{* *}$ & .03 & .06 \\
\hline $\begin{array}{l}\text { 10. Political views } \\
\text { (moral) }(N=627)\end{array}$ & 5.76 & 1.67 & & & & & & & & & & $.21^{* *}$ & .02 \\
\hline $\begin{array}{l}\text { 11. Political views } \\
\text { (economic) } \\
(N=627)\end{array}$ & 4.20 & 1.87 & & & & & & & & & & & .04 \\
\hline $\begin{array}{l}\text { 12. Education } \\
(\mathrm{N}=627)\end{array}$ & 5.27 & 1.13 & & & & & & & & & & & \\
\hline
\end{tabular}

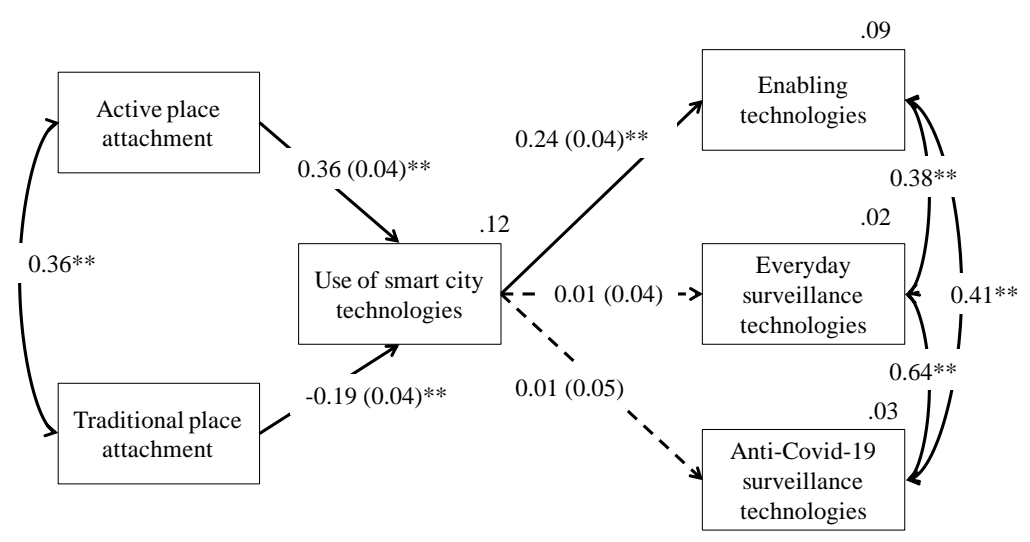

Figure 1. Indirect effect of two types of place attachment use of smart technologies on acceptance of future smart city technologies. 
Note. Standardized coefficients with a standard error (in brackets) are presented. For reasons of clarity, the total and direct effects of independent variables were omitted. Dashed lines represent nonsignificant coefficients.

\section{Discussion}

New smart city technologies are becoming more and more ubiquitous in cityscapes. While these technologies have been praised by many as a sign of progress and a way to make life easier, others claim that they represent a disturbing change in their beloved city. An increasing number of voices have emphasised that smart city implementation should consider the opinions of citizens, with planners seeking to understand their needs and concerns [5]. For this reason, the aim of our research was to provide evidence that attitudes towards technologies that have been or will be introduced are shaped by place attachment, an emotional bond that one has with a city. The second aim was to examine whether the relationship between place attachment and acceptance of new technologies is at least partially explained by one's current experience with smart city technologies.

Numerous studies have shown that place attachment is not a uniform phenomenon [15], [63]; thus, in our study, we included two types of emotional bonds with a place, assuming that they may have a distinct impact on acceptance of new technologies in a city. Indeed, the results show that both active place attachment and traditional place attachment are related to acceptance of future smart city technologies, but in different ways. Active attachment to a city predicted a more favourable attitude towards enabling technologies, while traditional attachment with a city was negatively associated with attitudes towards enabling technologies. These results are in line with literature suggesting that actively attached people are generally more eager to explore a city and discover its different aspects and new possibilities [47]. Since they are more willing to engage with such novelties, they also have more positive attitudes towards future technologies that can be considered as facilitating urban life and citizens' mobility. Conversely, traditionally attached people are usually more concerned about changes in their city of residence, as they treat it as irreplaceable, the place in which they feel settled and to which they are accustomed. They appreciate that their relationship with the place is stable, and that they feel at home there [47]. Therefore, traditionally attached inhabitants may feel reluctant regarding the introduction of new smart city technologies, as these technologies may significantly change the mode of interaction with the place and require adaptation to a new and - at least initially more complex reality. The results were in the opposite direction with regards to the acceptance of everyday and Covid-19-specific surveillance technologies. In terms of active place attachment, we observed only a slightly positive relationship with acceptance of antiCovid-19 surveillance technologies; however, it did not reach the level of significance. This outcome may suggest that actively attached citizens may be relatively more in favour of technologies used to combat the pandemic than of permanent surveillance technologies. This interpretation seems plausible because the lockdown and restrictions associated with the pandemic were probably particularly burdensome for those who appreciate mobility and exploration of their city. Future research should examine this possibility more deeply, for example, by asking participants about the specific advantages and disadvantages of implementing both types of surveillance technologies.

In line with our hypothesis, traditionally attached citizens were more likely to accept surveillance technologies. Traditional attachment may be related to perceiving future monitoring technologies as providing increased safety and stability and effectively protecting the city from, for example, crime or vandalism. For traditionally attached people, these issues may be an even greater concern than for others because this type of attachment is quite conservative in nature, as it is focused on stability, rootedness and low mobility. Many studies have shown that political conservatism is linked to a stronger security orientation [48][49] and, for example, a greater sense of threat due to infectious diseases [64]. Thus, city-focused conservatives, as one may call traditionally attached citizens, may also feel a greater willingness to accept technology that protects their place of residence from everyday dangers or the Covid-19 pandemic. Moreover, traditionally attached people may perceive future surveillance technologies as rather similar to existing monitoring technologies and therefore not related to significant changes in the cityscape and everyday habits. With the notable exception of monitoring drones, the other types of surveillance technologies examined in our study can be unobtrusively integrated into commonly used urban monitoring systems. Future research should examine to what extent the 'invisibility' of technology influences its acceptance by traditionally attached inhabitants.

Regarding the relationship between the two types of place attachment and the use of existing smart city technologies, we again observed a similar pattern as with acceptance of future enabling technologies. Higher levels of active and traditional attachment were, respectively, positively and negatively correlated with more frequent use of current technologies. Moreover, the use of smart city technologies was related only to attitudes towards enabling technologies. Use of 
existing technologies in the enabling and facilitating categories may thus translate into attitudes towards solutions similar in nature and meeting the same needs, but does not explain acceptance of surveillance technology. This outcome is in line with hypothesis and literature [60] emphasising the role of similarity in experience and attitude transfer.

Finally, we showed that use of existing technologies fully mediated the positive relation between active place attachment and acceptance of enabling technologies. Thus, an active relation with a city also encompasses active use of available technologies and further translates into a more positive attitude towards future enabling technologies. At the same time, use of smart city technologies partially mediated the negative effect of traditional attachment on acceptance of enabling technologies. It is probable then that relation between traditional bond with a place and attitude towards enabling technologies may be explained not only by the current activity related to smart city technologies but also by the type of mind-set and values that are associated with traditional place attachment.

\subsection{Limitations and future studies}

Our research is not free of limitations. Since our study was correlational, it did not allow us to establish causal relations. Although current place attachment could plausibly impact attitudes towards both existing and future technologies, smart city technologies, once introduced in cities, may also impact people-place bonds e.g. [65], [66].Future studies should thus further examine the relationship between attachment to a city and smart city technologies. This relationship should also be examined in cities that differ with regards to levels of technological development.

The second limitation is that people that participated in the study were slightly better educated than average and that limits our conclusion to this group of citizens. However, in the analyses we controlled for level of education and showed that the main effects still held true.

In our model, we only included the use of smart city technologies and did not measure the attitude towards these technologies and the actual level of user satisfaction. Adding these variables to the model could further enhance understandings of the mechanism underlying the relation between place attachment and acceptance of enabling technologies.

Similarly, future studies could examine the mechanism behind the relation between traditional place attachment and surveillance technologies. Since traditionally attached people are usually more concerned about the stability and protection of their residence place than are their peers, examining individual differences that may underlie the relation between this type of attachment and acceptance of surveillance technologies - for example, the need for security and perceived personal threat - may be worthwhile. Previous research [61] showed that perceived threat, for example, is a significant predictor of attitudes towards anti-Covid-19 tracking technologies.

City attachment and acceptance of future technologies, especially surveillance technologies, may be affected by other relevant factors, such as residents' support for municipal initiatives or trust in city council actions, which could be included as potential moderators in future studies.

\subsection{Conclusion}

In summary, our study contributes to the knowledge base regarding two important topics: 1) the relationship between place attachment and attitudes towards changes to places and 2) predictors of acceptance of new technologies in cities. We showed that acceptance of technological changes in a city can be affected by the type of emotional bond one has with the place, as well as by the type of technology. While active place attachment can encourage one to explore the possibilities afforded by new enabling technologies, traditional place attachment is related to higher scepticism towards futuristic solutions, except surveillance technologies, regarding both everyday monitoring and anti-pandemic measures. The results may have a wide range of implications for city governments, planners and businesses aiming to develop and implement smart cities solutions. On the one hand, municipal authorities should make a particular effort to understand the perspective of traditionally attached inhabitants, who may worry that new technologies will change their way of life and transform their city into an alien and unrecognisable place. On the other hand, actively attached citizens may be seen as natural, more willing users and testers of current and new urban technologies. However, as the new technologies examined in our study have not yet been implemented in most cities of the world, future studies should examine what will determine their level of satisfaction with a given solution and their motivation for further use or acceptance.

\section{Acknowledgments}

This paper was financed from the funds of the Polish National Science Centre No 2018/30/E/HS6/00379.

\section{References}


[1] S. King, \& S. Cotterill, "Transformational government? The role of information technology in delivering citizencentric local public services". Local Government Studies, 33(3), 2007, pp. 333-354.

[2] Belanche, D., Casaló, L. V., \& Orús, C. "City attachment and use of urban services: Benefits for smart cities", Cities, 50, 2016, pp. 75-81.

[3] N. Singer, \& C. Sang-Hun, "As coronavirus surveillance escalates, personal privacy plummets". The New York Times. 2020, March 23

[4] O. Wainwright "10 Covid-busting designs: spraying drones, fever helmets and anti-virus snoods". The Guardian, 2020, March 25

[5] M.S. Sepasgozar, S.Hawken, S. Sargolzaei, \& M. Foroozanfa,"Implementing citizen centric technology in developing smart cities: A model for predicting the acceptance of urban technologies", Technological Forecasting and Social Change, 142, 2019, pp. 105-116.

[6] O. Söderström, "From a technology intensive to a knowledge intensive smart urbanism. Beware of smart people", 2016, pp. 63-69

[7] R. Kitchin, "Making sense of smart cities: addressing present shortcomings", Cambridge journal of regions, economy and society, 8(1), 2015, pp. 131-136.

[8] Hirsch, E., and R. Silverstone, (Eds.), Consuming technologies: Media and information in domestic spaces, Routledge, London and New York, 2003

[9] D. Murthy, "Digital ethnography: An examination of the use of new technologies for social research", Sociology, 42(5), 2008, pp. 837-855.

[10] R.E. Kraut, S.R. Fussell, S.E. Brennan, and J. Siegel, Understanding effects of proximity on collaboration: Implications for technologies to support remote collaborative work. In: Distributed work, MIT Press, Cambridge, 2002, pp. 137-162.

[11] Coleman, S., and J.G. Blumler, The Internet and democratic citizenship: Theory, practice and policy. Cambridge University Press, Cambridge, 2009.

[12] C. Martelli, "A point of view on new education for smart citizenship", Future Internet, 9(1), 4, 2017, pp. 1-17.

[13] J. Lee, and H. Lee, "Developing and validating a citizencentric typology for smart city services", Government Information Quarterly, 31, 2014, pp. 93-105.

[14] P. Devine-Wright, "Explaining "NIMBY" objections to a power line: The role of personal, place attachment and project-related factors", Environment and behavior, 45(6), 2013, pp. 761-781.

[15] M. Lewicka, "Place attachment: How far have we come in the last 40 years?", Journal of environmental psychology, 31(3), 2011, pp. 207-230.

[16] L. Cuba, and D.M. Hummon, "A place to call home: Identification with dwelling, community, and region", Sociological quarterly, 34(1), 1993, pp. 111-131.

[17] M.C. Hidalgo, \& B. Hernandez, "Place attachment: Conceptual and empirical questions", Journal of environmental psychology, 21(3), 2001, pp. 273-281.

[18] B. Brown, D.D. Perkins, D. D., and G. Brown, "Place attachment in a revitalizing neighborhood: Individual and block levels of analysis", Journal of environmental psychology, 23(3), 2003, pp. 259-271.
[19] M. Lewicka, "What makes neighborhood different from home and city? Effects of place scale on place attachment", Journal of environmental psychology, 30(1), 2010, pp. 35-51. [20] M. Billig, R. Kohn, and I. Levav, "Anticipatory stress in the population facing forced removal from the Gaza Strip", The Journal of nervous and mental disease, 194(3), 2006, pp. 195-200.

[21] G.L. Theodori, "Examining the effects of community satisfaction and attachment on individual well-being", Rural sociology, 66(4), 2001, pp. 618-628.

[22] T. Hartig, F. Kaiser, \& P. Bowler, "Psychological restoration in nature as a positive motivation for ecological behavior", Environment \& behavior, 33(4), 2001, pp. 590.

[23] S. Mazumdar, \& S. Mazumdar, "Religion and place attachment: A study of sacred places", Journal of environmental psychology, 24(3), 2004, pp. 385-397.

[24] Low, S. M., and I. Altman, Place attachment. In: Place attachment, Springer, Boston, MA, 1992

[25] E. Gosling, and K.J. Williams, "Connectedness to nature, place attachment and conservation behaviour: Testing connectedness theory among farmers", Journal of environmental psychology, 30(3), 2010, pp. 298-304.

[26] E.A. Halpenny, "Pro-environmental behaviours and park visitors: The effect of place attachment", Journal of environmental psychology, 30(4), 2010, pp. 409-421.

[27] M. Vorkinn, and H. Riese, "Environmental concern in a local context: The significance of place attachment", Environment and behavior, 33(2), 2001, pp. 249-263.

[28] M. Lewicka, "Ways to make people active: The role of place attachment, cultural capital, and neighborhood ties", Journal of environmental psychology, 25(4), 2005, pp. 381395.

[29] P. Devine-Wright, and Y. Howes, "Disruption to place attachment and the protection of restorative environments: A wind energy case study", Journal of environmental psychology, 30(3), 2010, pp. 271-280.

[30] M. Prusik, T. Oleksy, A. Wnuk, and A.M. Kula, „Attitudes Towards Places Associated With Communism", Social Psychological Bulletin, 14(2), 2019, pp. 1-24.

[31] N. Letki, "Does diversity erode social cohesion? Social capital and race in British neighbourhoods", Political Studies, 56(1),2008, pp. 99-126.

[32] T. Maloutas, and M. Pantelidou Malouta, "The glass menagerie of urban governance and social cohesion: concepts and stakes/concepts as stakes", International Journal of Urban and Regional Research, 28(2), 2004, pp. 449-465.

[33] Brown, B. B., \& Perkins, D. D. Disruptions in place attachment. In: Place attachment, Springer, Boston, MA, 1992

[34] H.M. Proshansky, A.K. Fabian, and R. Kaminoff, "Place-identity: Physical world socialization of the self", Journal of environmental psychology, 3(1), 1983, pp. 57-83.

[35] C.K. Cheng, C. K., and S.F. Chou, "The influence of place change on place bonding: A longitudinal panel study of renovated park users", Leisure Sciences, 37(5), 2015, pp. 391-414.

[36] M. Scopelliti, \& L. Tiberio, "Homesickness in university students: The role of multiple place attachment", Environment and behavior, 42(3), 2010, pp. 335-350.

[37] L.M. Vandemark, "Promoting the sense of self, place, and belonging in displaced persons: The example of 
homelessness", Archives of psychiatric nursing, 21(5), 2007, pp. 241-248.

[38] K. Chow, and M. Healey, "Place attachment and place identity: First-year undergraduates making the transition from home to university", Journal of Environmental Psychology, 28(4), 2008, pp. 362-372.

[39] S, Christiaanse, and T. Haartsen, "The influence of symbolic and emotional meanings of rural facilities on reactions to closure: The case of the village supermarket", Journal of Rural Studies, 54, 2017, pp. 326-336.

[40] S. Christiaanse, and T. Haartsen, "Experiencing placechange: A shared sense of loss after closure of village facilities", Journal of Environmental Psychology, 69, 2020

[41] L.C. Manzo, and D.D. Perkins, "Finding common ground: The importance of place attachment to community participation and planning", Journal of planning literature, 20(4), 2006, pp. 335-350.

[42] R. Barnett, R., and P. Barnett, "“'If you want to sit on your butts you'll get nothing!" Community activism in response to threats of rural hospital closure in southern New Zealand", Health \& place, 9(2), 2003, pp. 59-71.

[43] L. Verbrugge, and R. van den Born, "The role of place attachment in public perceptions of a re-landscaping intervention in the river Waal", Landscape and urban planning, 177, 2018, pp. 241-250.

[44] T. Von Wirth, A. Grêt-Regamey, C. Moser, and M. Stauffacher, "Exploring the influence of perceived urban change on residents' place attachment", Journal of environmental psychology, 46, 2016, pp. 67-82.

[45] Norris, P., Digital divide: Civic engagement, information poverty, and the Internet worldwide. Cambridge University Press, Cambridge, 2003

[46] D. Eckhoff, and I. Wagner, "Privacy in the smart cityapplications, technologies, challenges, and solutions", IEEE Communications, 20(1), 2017, pp. 489-516.

[47] M. Lewicka, “On the varieties of people's relationships with places: Hummon's typology revisited", Environment and Behavior, 43(5), 2011, pp. 676-709.

[48] A. Malka, C.J. Soto, M. Inzlicht, M., \& Y. Lelkes, "Do needs for security and certainty predict cultural and economic conservatism?A cross-national analysis", Journal of Personality and Social Psychology, 106(6), 2014, pp. 10311051.

[49] J.T. Jost, J.L. Napier, H. Thorisdottir, S.D. Gosling, T.P. Palfai, T. P., \& B. Ostafin, "Are needs to manage uncertainty and threat associated with political conservatism or ideological extremity?", Personality and Social Psychology Bulletin, 33, 2007, pp. 989-1007

[50] C.M. Raymond, G. Brown, \& G.M. Robinson, "The influence of place attachment, and moral and normative concerns on the conservation of native vegetation: A test of two behavioural models", Journal of Environmental Psychology, 31(4), 2011, pp. 323-335.

[51] G. Kyle, A. Graefe, R. Manning, R., \& J. Bacon, "Effect of activity involvement and place attachment on recreationists' perceptions of setting density", Journal of leisure Research, 36(2), 2004, pp. 209-231.

[52] N. López-Mosquera, and M. Sánchez, "Direct and indirect effects of received benefits and place attachment in willingness to pay and loyalty in suburban natural areas", Journal of Environmental Psychology, 34, 2013, pp. 27-35.
[53] S. Zenker, and N. Rütter, "Is satisfaction the key? The role of citizen satisfaction, place attachment and place brand attitude on positive citizenship behavior", Cities, 38, 2014, pp. 11-17.

[54] D.D. Perkins, B.B. Brown, B. B., and R.B. Taylor, "The ecology of empowerment: Predicting participation in community organizations", Journal of Social Issues, 52(1), 1996, pp. 85-110.

[55] J.P. Zmud, and I.N. Sener, "Towards an understanding of the travel behavior impact of autonomous vehicles", Transportation research procedia, 25, 2017, pp. 2500-2519.

[56] C. Lee, C. Ward, M. Raue, L. D'Ambrosio, and J.F. Coughlin, Age differences in acceptance of self-driving cars: A survey of perceptions and attitudes. In International Conference on Human Aspects of IT for the Aged Population (pp. 3-13). Springer, Cham, 2017, July

[57] C. Hohenberger, C. Lee, and J.F. Coughlin, "Acceptance of robo-advisors: Effects of financial experience, affective reactions, and self-enhancement motives" Financial Planning Review, 2(2), 2019, e1047.

[58] M.A. Harris, R. Brookshire, and A.G. Chin, "Identifying factors influencing consumers' intent to install mobile applications", International Journal of Information Management, 36(3), 2016, pp. 441-450.

[59] K. Arning, and M. Ziefle, "Understanding age differences in PDA acceptance and performance", Computers in Human Behavior, 23(6), 2007, pp. 2904-2927.

[60] V. Venkatesh, and M.G. Morris, "Why don't men ever stop to ask for directions? Gender, social influence, and their role in technology acceptance and usage behavior", MIS quarterly, 2000, pp. 115-139.

[61] A. Wnuk, T. Oleksy, \& D. Maison, "The acceptance of Covid-19 tracking technologies: situational and dispositional determinants", Manuscript submitted for publication, 2020.

[62] Muthén, L. K., \& Muthén, B. O, Mplus Version 7 user's guide. Los Angeles, 2012

[63] L. Scannell, L., and R. Gifford, "Defining place attachment: A tripartite organizing framework", Journal of environmental psychology, 30(1), 2010, pp. 1-10.

[64] J.M. Tybur, L.A. Merriman, A.E.C. Hooper, M.M. McDonald, M. M., and C. D. Navarrete, "Extending the behavioral immune system to political psychology: Are political conservatism and disgust sensitivity really related?". Evolutionary Psychology, 8(4), 2010

[65] T. Oleksy, and A. Wnuk, "Catch them all and increase your place attachment! The role of location-based augmented reality games in changing people-place relations", Computers in Human Behavior, 76, 2017, pp. 3-8.

[66] T. Oleksy, and A. Wnuk, "Augmented places: An impact of embodied historical experience on attitudes towards places", Computers in Human Behavior, 57, 2016, pp. 11-16.

[67] M. Kosinski, SC. Matz, SD. Gosling, V. Popov, D. Stillwell "Facebook as a research tool for the social sciences: Opportunities, challenges, ethical considerations, and practical guidelines", American Psychologist, 2015, 70(6), pp. 543-566. 